\title{
Pelatihan Penggunaan Kompor Biomassa Guna Meningkatkan Produktifitas Pedanggang Gorengan
}

\author{
Arif Setyo Nugroho ${ }^{1}$, Didik Achadi $W^{2}$, Y Yulianto Kristianto ${ }^{3}$ \\ ${ }^{1,3}$ Program Studi Teknik Mesin, STT Warga Surakarta, Sukoharjo, Indonesia. \\ $2^{2 *}$ Program Studi Kimia Tekstil, STT Warga Surakarta, Sukoharjo, Indonesia. \\ Email: arifsn@sttw.ac.id
}

\begin{abstract}
The implementation of community service is carried out by providing solutions for fried food traders who sometimes experience problems, especially regarding the process of making merchandise for sale. The problem that arises is how to utilize solid waste from biomass in the form of wood as fuel when the process of making fried food, the hope is to reduce production operational costs and reduce waste around. The solution given is to use a biomass waste fuel stove, namely wood or charcoal, a stove with a gasification system. Utilization of wood waste and biomass as fuel can be a solution when LPG is scarce or the availability of wood waste is abundant. By calculation, using wood waste for cooking requires approximately $6 \mathrm{~kg}$, economically it is cheaper because it utilizes biomass waste that is around. The disadvantage of using wood waste fuel is regarding the combustion residue, namely ash.
\end{abstract}

Keywords: Stove, Gasification, Biomass Waste, Economical, Ash.

\begin{abstract}
Abstrak
Pelaksanaan pengabdian kepada masyarakat dilaksanakan dengan memberikan solusi bagi pedagang gorengan yang terkadang mengalami permasalahan terutama mengenai proses pembuatan dagangan untuk dijual. Permasalahan yang muncul adalah bagaimana memanfaatkan limbah padatan dari biomassa yang berupa kayu menjadi bahan bakar ketika proses membuat makanan gorengan, harapannya adalah bisa menekan biaya operasional produksi dan mengurangi limbah yang ada di sekitar. Solusinya yang di berikan adalah dengan menggunakan kompor bahan bakar limbah biomassa yaitu kayu atau arang, kompor dengan sistem gasifikasi. Pemanfaatan limbah kayu dan biomassa sebagai bahan bakar dapat menjadi solusi ketika LPG langka atau ketersediaan dari limbah kayu berlimpah. Secara perhitungan, menggunakan limbah kayu untuk memasak membutuhkan kurang lebih $6 \mathrm{~kg}$, secara ekonomis lebih murah karena memanfaatkan limbah biomassa yang ada disekitar. Kelemahan menggunakan bahan bakar limbah kayu adalah mengenai sisa pembakaran yaitu abu.
\end{abstract}

Kata Kunci: Kompor, Gasifikasi, Limbah Biomassa, Ekonomis, Abu.

\section{A. PENDAHULUAN}

Pedagang gorengan dijumpai di sekitar tempat tinggal kita, mereka menjual gorengan dengan gerobak keliling atau berhenti di tempat tertentu. Ada yang dijual sendiri maupun dititipkan ke pedagang lain. Tentunya pedagang gorengan tersebut terlihat tanpa masalah, ternyata ada masalah terutama bagaimana meningkatkan pendapatan dengan mengefisiensikan bahan bakar, dengan bahan bakar menggunakan bahan bakar limbah biomassa. Secara umum, pertumbuhan ekonomi sangat berpengaruh terhadap kebutuhan energi, dengan ketersediaan energi dapat mendorong pertumbuhan ekonomi dan pembangunan (Haryana, 2019) .
Biomassa adalah sumber energi yang bisa diperbaruhi berasal dari tumbuhan. Pemanfaatan limbah biomasa sebagai sumber bahan bakar alternative karena limbah biomassa tersebut masih mempunyai kandungan energi. Ketergantungan masyarakat terhadap energi fosil masih tinggi dan cadangan energy dari fosil semakin menipis maka diperlukan energi alternative dari limbah biomassa yang berasal dari pertanian (Selilana dkk., 2017). Dengan penggunaan bahan bakar dari limbah biomassa sebagai bahan bakar alternative dapat mengurangi ketergantungan penggunaan bahan bakar dari fosil maupun LPG (Fadilah dkk., 2019). Biomassa memiliki sifat dan karakteristik yang hamper berbeda beda, sekam padi memiliki berat jenis sekitar $122 \mathrm{~kg} / \mathrm{m}$, sekam padi memiliki sifat jumlah abu hasil pembakaran yang tinggi, 
temperatur titik lebur abu yang rendah, kandungan uap air pada sekam padi kecil. Kayu jati sebagian besar terdiri dari selulosa: $47.5 \%$, lignin $29.9 \%$. Sifat dan Karakter yang dimiliki kayu sengon adalah mimiliki lignin $37.31 \%$, hemiselulosa $45.35 \%$, selulosa $52.14 \%$, kadar air $2.91 \%$, dan kadar abu sebesar 1.26\% (Fadilah dkk., 2019).

Di daerah Surakarta banyak dijumpai pengusaha mebel yang menghasilkan limbah kayu dari proses produksi mebel yang mereka buat, limbah kayu yang belum maksimal penggunaannya dan terkadang hanya dibakar saja belum dimanfaatkan secara maksimal. Sekitar kota Surakarta juga masih banyak area persawahan yang menghasilkan limbah pertanian padi yaitu sekam padi yang belum bisa dimanfaatkan secara maksimal. Berdasarkan potensi sekam padi dan tatal kayu yang begitu besar sebagai sumber energi maka sangat memungkinkan penggunaan limbah tersebut sebagai bahan bakar alternatif pengganti energi kayu atau bahan bakar minyak sebagai solusi alternative ketika LPG langka dan pemanfaatan limbah biomassa disekitar lingkungan. Untuk pemanfaatan biomassa tersebut diperlukan kompor yang bisa menghasilkan nyala yang bagus, tidak berjelaga dan memiliki nilai kemanfaatan yang tinggi. Pemanfaatan limbah biomassa bisa mengurangi polusi lingkungan (A. S. Nugroho, 2019) .

Prinsip dasar kompor adalah sebagai sarana proses pembakaran bahan bakar. Proses pembakaran adalah reaksi kimia antara bahan bakar dan oksigen. Pada proses ini perlu diperhatikan rasio antara jumlah bahan bakar dan oksigen (yang diwakili oleh laju aliran udara) yang tepat sehingga proses pembakaran mendekati sempurna. Laju aliran massa pada setiap bahan bakar berbeda beda yang menghasilkan panas yang berbeda-beda pula. Laju perpindahan panas meningkat seiring jalannya waktu perpindahan panas dan waktu pembakaran serta kecepatan udara yang dimasukan (Sulaiman dkk, 2018). Selanjutnya juga perlu dipertimbangkan masalah biaya, kemudahan operasi dan pemeliharaan kompor, Kinerja dari tungku tergantung dari karakteristik pembakaran yaitu meliputi waktu, temperature dan kualitas udara pembakaran (Mandasini dkk., 2016).

Kompor secara umum memiliki beberapa bagian utama dengan fungsi masing -masing yang antara lain meliputi tempat bahan bakar (minyak atau limbah biomasa), tungku pembakaran dan aliran udara alami. Dalam pembuatan kompor biomassa yang harus diperhatikan adalah kualitas nyala api, cara penyalaan dan penambahan bahan bakar ( $R$ Wakir dkk., 2016). Konstruksi kompor sangat berpengaruh terhadap kualitas nyala api dan penambahan bahan baku (Purnomo dkk., 2015) Kompor berbahan bakar biomasa mempunyai tambahan bagian penting lainnya untuk proses pembakaran, yaitu tempat penampung abu dan aliran udara paksa (blower). Konstruksi kompor dengan ditambahi blower dimaksudkan untuk mengarahkan api dan bara sehingga apinya lebih berkualirtas dan kompor dengan bahan bakar biomassa lebih effektif (Santoso, 2018). Kompor berbahan bakar biomassa menggunakan blower tekanan rendah alkan menghasilkan api yang baik, besar dan kecilnya api tergantung dari suplai udara yang masuk dalam kompor (Armansyah dkk., 2020). Kompor biomassa adalah kompor yang digunakan untuk menggantikan kompor berbahan bakar minyak atau LPG ketika ada permasalahan (Zakariya dkk., 2020)

\section{B. PELAKSAAAN DAN METODE}

\section{Identifikasi Masalah}

Permasalahan yang dihadapi beberapa pedagang kecil yaitu bagaimana cara memperkecil pengeluaran terutama untuk membeli bahan bakar dan menghindari permasalahan ketika bahan bakar dari fosil atau gas langka dari pasaran, penjualan tetap berlangsung dengan kompor system biogas dan berbahan bakar limbah biomassa berupa kayu yang ada di sekitar.

\section{Solusi Yang Diterapkan}

Solusi yang di tawarkan adalah kompor berbahan bakar biomassa dengan sistem gasifikasi. Bahan baku yang digunakan adalah arang dan limbah biomassa disekitar yang kering, Konstruksi kompor menggunakan plat besi yang dibentuk sedemikian rupa, sumber hembusan angina menggunakan blower 2". Hembusan angina berbentuk spiral naik ke atas dan diharapkan dapat menambah besarnya nyala api.

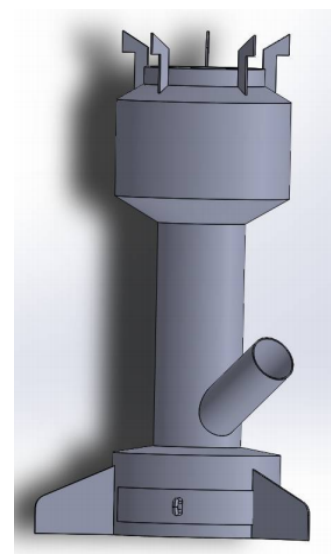

Gambar 1. Rencana kompor yang dikembangkan

\section{Tahapan Pelaksanaan Pengabdian}

Dalam pelaksanaan kegiatan pengabdian dilakukan tahapan pelaksanaan. Tahapan pelaksanaan kegiatan adalah sebagai berikut : 


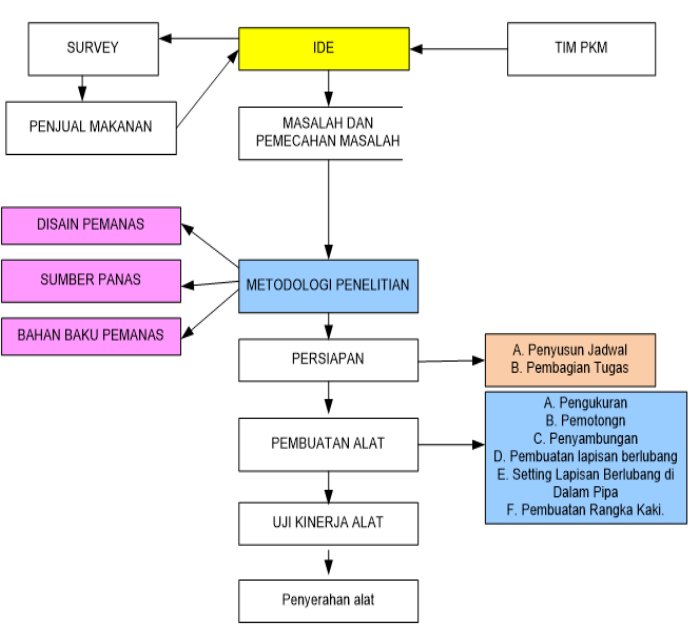

Gambar 2. Tahapan Pelaksanaan kegiatan

\section{Disain alat}

Kompor berbahan bakar biomasa ini terdiri atas beberapa bagian utama yaitu tabung reaktor, wadah abu di bagian bawah tabung (menyatu dengan tabung reaktor), blower, tempat pembakaran (kompor). Tabung reaktor merupakan tempat biomasa dan tempat pembakaran biomasa sehinggga merubah biomasa menjadi energi untuk pembakaran menghasilkan api. Pembakaran di dalam tabung reaktor dibantu oleh oksigen yang disalurkan melalui pipa penghubung dari blower dan tabung reaktor. Kompor biomassa yang dibuat serangkai dengan tabung reaktor. Wadah abu dilengkapi pintu yang berfungsi untuk mengeluarkan abu sisa dari pembakaran yang terjadi pada tabung reaktor. Pintu pada saat operasi harus dalam keadaan tertutup agar tak terjadi pertukaran udara dari tabung reaktor dan lingkungan. Tabung reaktor terbuat dari bahan plat besi datar dengan tebal $0,2 \mathrm{~mm}$ dibuat membentuk tabung. Reaktor dibentuk seperti tabung untuk mempermudah proses pengaliran oksigen di dalam tabung sehingga lebih mudah terjadinya proses pembakaran. Tabung reaktor terdiri dari 2 tabung yaitu tabung luar dan tabung dalam. Tabung luar berdiameter $25 \mathrm{~cm}$ dan tabung dalam berdiameter $20 \mathrm{~cm}$. Diantara kedua tabung diisi campuran semen dan abu sebagai isolator panas dengan komposisi perbandingan 2:1. Tujuan menggunakan campuran abu dan semen karena abu dan semen merupakan isolator panas yang cukup baik. Tabung reaktor dilengkapi penutup tabung yang terbuat dari plat besi dengan tebal $2 \mathrm{~mm}$. Tinggi kompor total adalah $50 \mathrm{~cm}$. Wadah abu dibuat dengan plat besi dengan tebal $0,2 \mathrm{~mm}$. Wadah abu berukuran dengan pxlxt yaitu $(44,5 \times 38,5 \times 12,5) \mathrm{cm}$. Di dalam wadah abu terdapat kotak abu yang terbuat dari aluminium dengan tebal $0,5 \mathrm{~mm}$. Kotak abu sebagai tempat abu hasil dari pembakaran di tabung memiliki ukuran sisi - sisi $24,5 \mathrm{~cm}$ dan tinggi $5 \mathrm{~cm}$.

\section{Analisa Teknik}

Kompor yang dibuat berbentuk vertikal dengan hembusan paksa dari blower, diharapkan hembusan angin berbentuk spiral sehingga masuk ruang bakar dapat memperbesar api yang menyala.

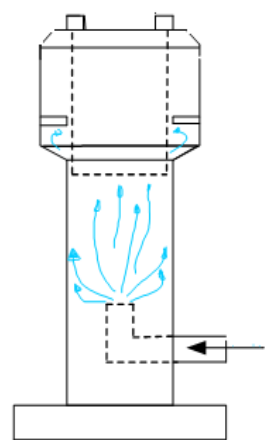

Gambar 3. Arah hembusan angin

\section{Investasi Alat}

Investasi alat sangat murah dan cara mengoperasikan tidak perlu ketrampilan khusus, sehingga sangat membantu pedagang kecil dalam berjualan.

\section{Hasil dan Pembahasan}

Konstruksi kompor vertical sangat mudah dibuat dan digunakan sehingga bila ada yang ingin membuat dan digunakan tinggal menirunya. Dengan menggunakan kompor vertical, bisa lebih meningkatkan produksi dan produktifitas. Tentunya yang diharapkan adalah hasil yang lebih banyak dan akhirnya bisa menambah penghasilan. Kompor vertikal berbahan bakar limbah biomassa tersebut di serahkan untuk dipergunakan sebagaimana yang diharapkan. Kegiatan Pelatihan tersebut bisa dilihat dari gambar dibawah ini :

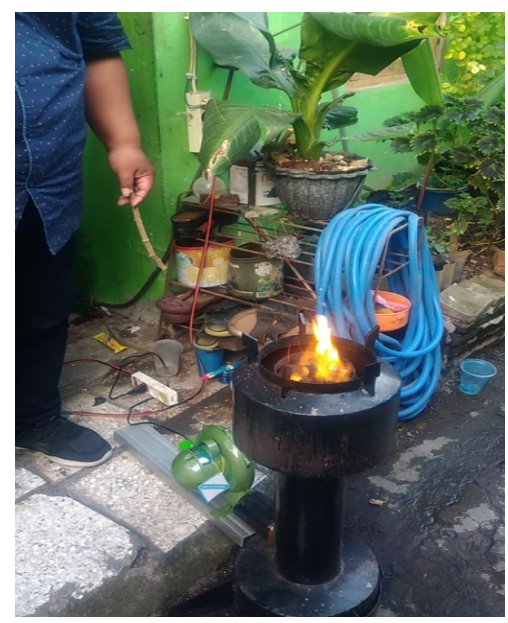

Gambar 4. Penyalaan bahan bakar di kompor

Gambar 4 menjelaskan bagaimana cara menggunakan kompor vertikal dengan bahan bakar 
biomassa, kompor yang digunakan diletakan pada tanah yang datar sehingga beban menjadi imbang. Langkah pertama yaitu memasukan bahan bakar berupa limbah kayu atau arang, nyalakan buat bara api, kemudian letakan panci atau wajan untuk memasak. Kemudian nyalakan blower, atur kencang dan lambatnya anginya. Arang adalah bahan bakar yang berasal dari biomassa yang telah melalui proses pengarangan atau karbonisasi (W. A. Nugroho dkk., 2016).

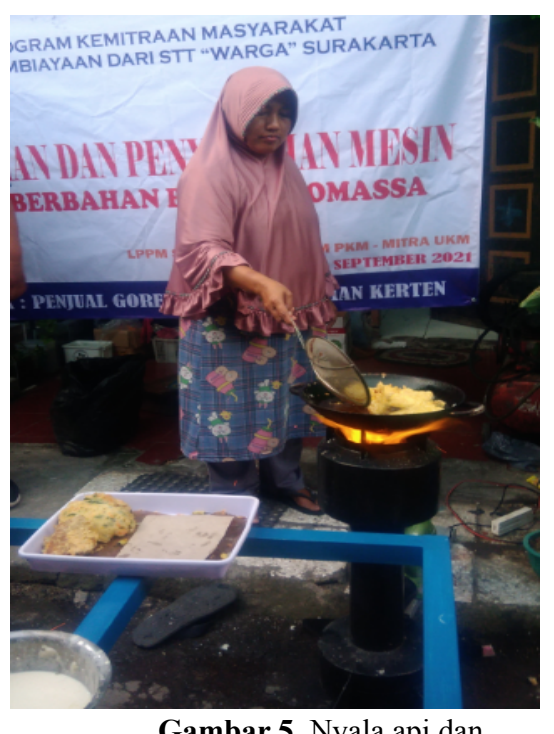

Gambar 5. Nyala api dan pelatihan penggunaan kompor.

Gambar 5 menjelaskan mengenai bentuk nyala dari kompor vertical, nyala berwarna orange cerah dengan jelaga yang sedikit. Sebelum di serahkan pada pedagang kecil, diuji coba dengan memanaskan air sebanyak 1 liter dengan wktu pendidihan kurang lebih 4 menit 18 detik dengan bahan bakar tempurung kelapa kering, membutuhkan bahan bakar kurang lebih 231 gram tempurung kelapa. Bila dalam memanaskan air 1 liter memerlukan bahan bakar lebih banyak dibandingkan dengan bahan bakar lain maka bahan bakar tersebut memiliki effisiensi yang rendah (W. A. Nugroho dkk., 2016).

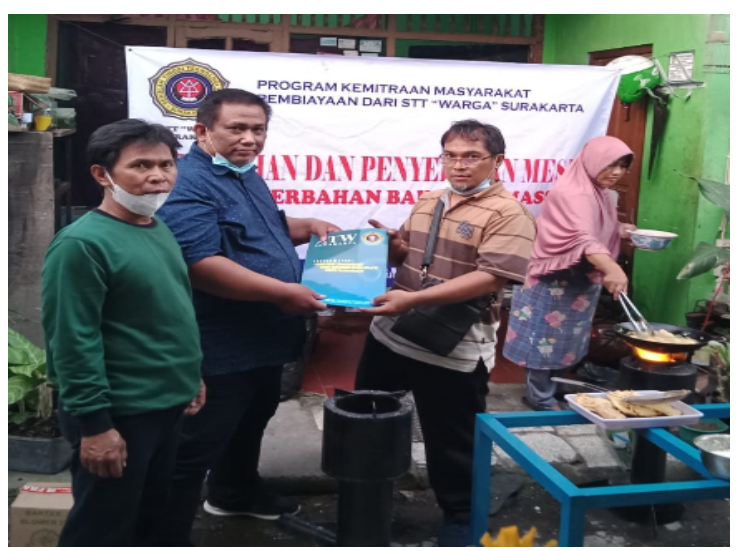

Gambar 6. Penyerahan kompor untuk 2 UKM penjual gorengan.
Secara perhitungan ekonomis, bila menggunakan bahan bakar LPG $3 \mathrm{~kg}$ bisa digunakan selama 2 hari untuk menggoreng dagangan yang berupa pisang goreng, bakwan dan tempe goreng, dengan harga gas $3 \mathrm{~kg}$ kurang lebih 19 ribu rupiah. Tetapi bila menggunakan limbah kayu untuk memasak membutuhkan kurang lebih 6 $\mathrm{kg}$, secara ekonomis lebih murah karena memanfaatkan limbah. Kelemahan menggunakan bahan bakar limbah kayu adalah mengenai sisa pembakaran yaitu abu, keuntungan penggunaan LPG adalah area untuk menggoreng bersih tidak ada abu. tetapi bila secara keseluruhan masih unggul menggunakan LPG. Bila biomassa yang digunakan diolah menjadi pellet, arang atau briket tentunya memiliki nilai lebih baik dibandingkan dengan masih berbentuk kayu (Wibowo, 2020).

Bila menggunakan kompor biomassa konvensional maka akan menghasilkan asap yang lebih banyak, maka kompor yang di gunakan adalah kompor gasifikasi yang memerlukan udara lebih sedikit gas yang dibakar lebih kecil polusinya, jelaga yang dihasilkan juga lebih sedikit (Supramono dkk, 2015). Penggunaan kompor system gasifikasi lebih irit bila dibandingkan pembakaran biasa dengan menggunakan bahan kayu (Santoso, 2018).

\section{HASIL DAN PEMBAHASAN}

Secara perhitungan ekonomis, bila menggunakan bahan bakar LPG $3 \mathrm{~kg}$ bisa digunakan selama 2 hari untuk menggoreng dagangan yang berupa pisang goreng, bakwan dan tempe goreng, dengan harga gas $3 \mathrm{~kg}$ kurang lebih 19 ribu rupiah. Tetapi bila menggunakan limbah kayu untuk memasak membutuhkan kurang lebih 6 $\mathrm{kg}$, secara ekonomis lebih murah karena memanfaatkan limbah. Kelemahan menggunakan bahan bakar limbah kayu adalah mengenai sisa pembakaran yaitu abu, keuntungan penggunaan LPG adalah area untuk menggoreng bersih tidak ada abu. tetapi bila secara keseluruhan masih unggul menggunakan LPG. Bila biomassa yang digunakan diolah menjadi pellet, arang atau briket tentunya memiliki nilai lebih baik dibandingkan dengan masih berbentuk kayu (Wibowo, 2020).

Bila menggunakan kompor biomassa konvensional maka akan menghasilkan asap yang lebih banyak, maka kompor yang di gunakan adalah kompor gasifikasi yang memerlukan udara lebih sedikit gas yang dibakar lebih kecil polusinya, jelaga yang dihasilkan juga lebih sedikit (Supramono dkk, 2015). Penggunaan kompor system gasifikasi lebih irit bila dibandingkan pembakaran biasa dengan menggunakan bahan kayu (Santoso, 2018) .

\section{Simpulan}


Program kemitraan kepada Masyarakat atau lebih familier dengan nama pengabdian pada masyarakat dengan pendanaan dari kampus STT Warga Surakarta telah dilaksanakan. Program tersebut meliputi program pelatihan penggunaan dan penyerahan alat yang berupa kompor berbahan bakar biomassa dilengkapi dengan blower dengan sistem gasifikasi. Semoga dengan alat yang diberikan dapat dipergunakan secara maksimal dan dapat menghasilkan nilai tambah Mitra. Pemanfaatan limbah kayu dan biomassa sebagai bahan bakar dapat menjadi solusi ketika LPG langka atau ketersediaan dari limbah kayu berlimpah. Secara perhitungan ekonomis, bila menggunakan bahan bakar LPG $3 \mathrm{~kg}$ bisa digunakan selama 2 hari untuk menggoreng dagangan yang berupa pisang goreng, bakwan dan tempe goreng. Tetapi bila menggunakan limbah kayu untuk memasak membutuhkan kurang lebih 6 $\mathrm{kg}$, secara ekonomis lebih murah karena memanfaatkan limbah. Kelemahan menggunakan bahan bakar limbah kayu adalah mengenai sisa pembakaran yaitu abu,

\section{E. DAFTAR PUSTAKA}

Armansyah, D. H., Elfiano, E., \& Yulianto, D. (2020). Pemanfaatan Panas Pada Dinding Kompor Gasifikasi Biomassa Untuk Pembangkit Listrik DC Menggunakan Thermoelectric Generator. Journal Of Renewable Energy \& Mechanics ( REM), 03(02), 44-52.

Fadilah, C., Ch, P., Suwandi, D., Si, M., Iskandar, R. F., \& Pd, S. (2019). Pengaruh Jenis Biomassa Dan Kecepatan Aliran Udara Terhadap Kinerja Kompor Gasifikasi Biomassa. E- Proceeding of Engineering, 6(2), 5217-5224.

H, Wakur Rawung., D, M., Ludong, P. (2016). Kompor Biomassa Menggunakan Bahan Bakar Kayu Cengkeh ( Syzygium Aromatic ( L .) Merr) Sebagai Sumber Energi. Teknologi Pangan.

Haryana, A. (2019). Development of Biomass Energy Usage in the Household Sector and its Impact on LPG Subsidy Expenses and Poor Family Health. Bappenas Working Pappers, II(2), 176-190.

Mandasini, Sungkono, Pawennari, A., \&
Ahiruddin. (2016). Analisa Kinerja Tungku Berbahan Bakar Bio Briket. Journal of Chemical Process Engineering, 01(01), 25-30.

Nugroho, A. S. (2019). Pemanfaatan Limbah Tempurung Kelapa Sawit Sebagai Campuran Bahan Bakar Diesel. Prosiding SNST Ke 10, 21-26.

Nugroho, W. A., Lutfi, M., Braga, I., \& Nuriawan, A. (2016). Uji Kinerja Tungku Biomassa Menggunakan Blower Berdasarkan Variasi Tegangan Dan Jenis Bahan Bakar. Jurnal Keteknikan Pertanian Tropis Dan Biosistem, 4(3), 222-229.

Purnomo, R. H., Kuncoro, E. A., \& Wahyuni, D. (2015). Rancang Bangun Dan Uji Teknik Kompor Berbahan Bakar Limbah Biomassa Pertanian. Buana Sains, 14(2), 71-78.

Santoso, H. (2018). Rancang Bangun Kompor Biomassa Berbahan Dasar Plat Besi dan Beton Dilengkapi Dengan Teknologi Blower Hadi Santoso Heppi Iromo Abstrak. Jurnal Reaktom, 03(02), 22-25.

Selilana, E. A., Suwandi., \& Ayodha, T. (2017). Pengaruh Tinggi Dan Jumlah Lubang Udara Pada Tungku Pembakaran Serta Variasi Kecepatan Aliran Udara Terhadap Kinerja Kompor Gasifikasi Biomassa. E- Proceeding of Engineering, 4(3), 3862-3868.

Sulaiman, \& SR, I. (2018). Laju Perpindahan Panas Pada Tungku Biomassa Dengan Bahan Bakar Tempurung Kelapa Serbuk Kayu Dan Sekam Padi. Menara Ilmu, XII(79), 110-116.

Supramono, D., \& Winata, R. (2015). Unjuk Kerja Kompor Gas-Biomassa dengan Bahan Bakar Pellet Biomassa dari Limbah Bagas Tebu. Seminar Nasional Teknik Kimia Indonesia Dan Musyawarah Nasional Aptekindo, November.

Wibowo, N. I. (2020). Pemanfaatan teknologi tepat guna kompor roket dengan formulasi bahan bakar pelet kayu dan kayu sengon. Agroscience, 10(2), 136-147.

Zakariya, M. A., Irfai, M. A., \& Rosadi, M. M. (2020). Analisis Pengaruh Variasi Bahan Bakar Terhadap Uji Efektifitas Kompor Biomassa. ARMATUR, 01(02), 55-60. 